\title{
Coordinated Control of Reactive Power between STATCOMs and Wind Farms for PCC Voltage Regulation
}

\author{
Thanh Hai Nguyen", Dong-Choon Lee ${ }^{\dagger}$, Tan Luong Van ${ }^{* *}$, and Jong-Ho Kang ${ }^{* * *}$ \\ $\dagger^{*}$ Dept. of Electrical Engineering, Yeungnam University, Gyeongsan, Korea \\ ${ }^{* *}$ Ho Chi Minh City Electric Power College, Ho Chi Minh, Viet Nam \\ ${ }^{* * *}$ Wind Energy Biz Division, Hyosung Co., Ltd, Changwon, Korea
}

\begin{abstract}
This paper proposes a coordinated control of the reactive power between the STATCOMs (static synchronous compensators) and the grid-side converters (GSC) of wind farms equipped with PMSGs (permanent-magnet synchronous generators), by which the voltage fluctuations at the PCC (point of common coupling) are mitigated in the steady state. In addition, the level of voltage sags is reduced during grid faults. To do this, the GSC and the STATCOM supply reactive power to the grid coordinately, where the GSCs are fully utilized to provide the reactive power for the grid prior to the STATCOM operation. For this, the GSC capability of delivering active and reactive power under variable wind speed conditions is analyzed in detail. In addition, the PCC voltage regulation of the power systems integrated with large wind farms are analyzed for short-term and long-term operations. With this coordinated control scheme, the low power capacity of STATCOMs can be used to achieve the low-voltage ride-through (LVRT) capability of the wind farms during grid faults. The effectiveness of the proposed strategy has been verified by PSCAD/EMTDC simulation results.
\end{abstract}

Key Words: Coordinated control, GSC, Low-voltage ride-through, PCC voltage regulation, PMSG, STATCOM, Wind farms

\section{INTRODUCTION}

Nowadays, the penetration of wind power into the grid has been increasing continuously. As a result, its influence on the stability of existing power systems has become an important issue. In addition, this situation has changed the role of the wind power in the grid. Wind power plants are required to control the grid voltage and to enhance power system stability [1], [2]. Furthermore, for the security of power system operation, the disconnection of a significant number of wind turbine generators is no longer accepted [1], [3]-[5]. Fig. 1 shows the different grid codes for the LVRT requirements and the reactive current required to provide the grid with consideration of the voltage drop profile [3].

As for the power stability issues, the management of the

Manuscript received Jan. 28, 2013; revised Jul. 26, 2013

Recommended for publication by Associate Editor Seung-Ho Song.

${ }^{\dagger}$ Corresponding Author: dclee@yu.ac.kr

Tel: +82-53-810-2582, Fax: +82-53-810-4767, Yeungnam University

*Dept. of Electrical Eng., Yeungnam University, Korea

${ }^{* *}$ Ho Chi Minh City Electric Power College, Viet Nam

${ }^{* * *}$ Wind Energy Biz Division, Hyosung Co., Ltd., Korea
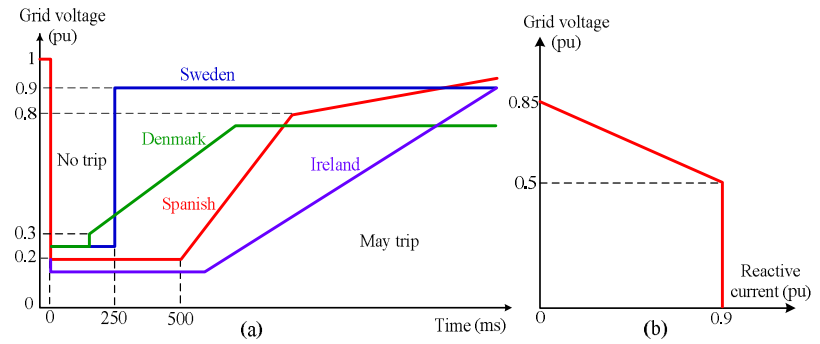

Fig. 1. Grid codes [3].

(a) LVRT requirements. (b) Amount of required reactive current of Spanish grid code.

reactive power exchanged between the wind farm and the grid is essential [6]. In order to comply with power factor requirements and voltage stability requirements at the PCC, most wind farms are equipped with switched-shunt capacitors for static reactive power compensation, especially in fixedspeed wind turbine systems. Today, variable-speed wind turbine (VSWT) systems are preferred to fix-speed systems [7]-[11], where the VSWT systems are controlled to 
maximize the active power production captured from the wind and to regulate the reactive power independently.

During normal operation, the output power of a wind turbine generator fluctuates due to variations in the wind speed, wind shear and tower shadow effects [12]. These power fluctuations cause the degradation of power quality such as voltage fluctuations, flickers, and system frequency deviations. Switched-shunt capacitor banks can be used to improve the steady-state voltage stability. However, shortterm voltage fluctuations (seconds to minutes) and harmonics cannot be solved due to the slow response of the switched capacitor banks [13]. Along with delivering active power to the grid, VSWTs can also provide reactive power to the grid by modifying the control structure without additional devices [1], [6], [14].

However, the reactive power production of wind turbines is limited, especially in the high-wind speed operation where large amounts of active power is delivered to the grid. In order to increase the reactive power capacity, a higher power rating of the GSCs of PMSG wind turbines has been suggested [15]. Unfortunately, this increases the system cost. In addition, the power losses of the system are increased as well. Another scheme to improve the power quality of wind farms integrated with the grid using a STATCOM has been introduced [13], [16]. The STATCOM provides several advantages such as a fast response (1-2 cycles) and superior voltage support capability due to its nature as a voltage source [17]. In addition, unlike shunt capacitor banks, the STATCOM is capable of generating reactive current for the grid under deep voltage sag conditions. However, the cost of the STATCOM is still high. By coordinating a large wind farm with a STATCOM for reactive power control, the power capacity of the STATCOM can be reduced [1]. However, the reduction of the STATCOM capacity is not significant due to the limitations of the generator capacity for reactive power control during grid fault conditions. The coordinated control of a STATCOM and a DFIG-based wind farm for optimizing the power loss of the system has been presented in [18]. The limitation of this approach is that the coordinated algorithm only takes the power loss into account, without considering the voltage regulation. Another method for the coordinated reactive power management in power networks with wind turbines and static VAR compensators (SVC) was presented [19], in which the objective of the optimization algorithm is to allocate a specified number of wind farms and SVC to improve the voltage stability. However, this method is complex due to its use of a generic algorithm.

In this paper, a novel coordinated reactive power control strategy for a STATCOM and the GSCs of PMSG wind turbines is proposed, by which the power quality of the power system with the integration of a large wind farm can be improved in both the steady-state and transient-state conditions. For this, the GSCs are fully utilized to provide reactive power for the grid prior to operating the STATCOM, where the reactive power production capability of each GSC depends on the amount of active power delivered. In addition, during a grid fault, the GSCs preferentially supply the reactive power to the grid, in which the active power generated from the PMSG is significantly reduced by storing the turbine output energy into the turbine inertia to accelerate the generator speed. Then, the low power capacity of the STATCOM can be used to achieve the LVRT capability of the wind farm during grid faults. PSCAD/EMTDC simulation results are shown to verify the validity of the proposed method.

\section{CONFIGURATION OF THE POWER System}

Fig. 2 shows a single-line diagram of the power system, which will be investigated in this paper. The power system is supplied mainly by a thermal generator at bus 1 , which is modeled as a three-phase infinite source. Buses 3 and 4, located far away from the generation area at bus 2 , are the load center with four loads. A wind farm is integrated into the grid at bus 4. It consists of variable-speed wind turbine systems equipped with PMSGs as shown in Fig. 3. The wind farm power capacity is insufficient to provide the local load. Therefore, the power demand from the load center is supplied through transmission from the main generation area.

For enhancing the power system stability, a STATCOM is placed at bus 4 , which can suppress short-term voltage fluctuations in the steady state. In addition, the STATCOM is able to assist PCC voltage recovery during and after grid faults.

\section{STATCOM MODEL AND THE REACTIVE POWER CAPABILITY OF GRID-SIDE CONVERTERS}

\section{A. Design and Control of a STATCOM}

A STATCOM is normally a type of voltage-source converter (VSC), which is connected to a network in parallel as shown in Fig. 4 [20]-[22]. A typical application for a STATCOM is to support the grid voltage by supplying reactive power. A control block diagram of a STATCOM is shown in Fig. 4, in which the DC-link voltage and the reactive power are regulated.

In the practical applications of a STATCOM, two-level full-bridge converters, three-level neutral point clamped (NPC) converters or cascaded multilevel converters are usually utilized, which employ self-commutated switches. The rating of a STATCOM should be determined appropriately according to the reactive power requirements for the power factor demand or the voltage regulation at the PCC. A larger capacity STATCOM is able to support short circuits longer during faults and shorten the voltage recovery process after the fault clearance [23], [24]. 


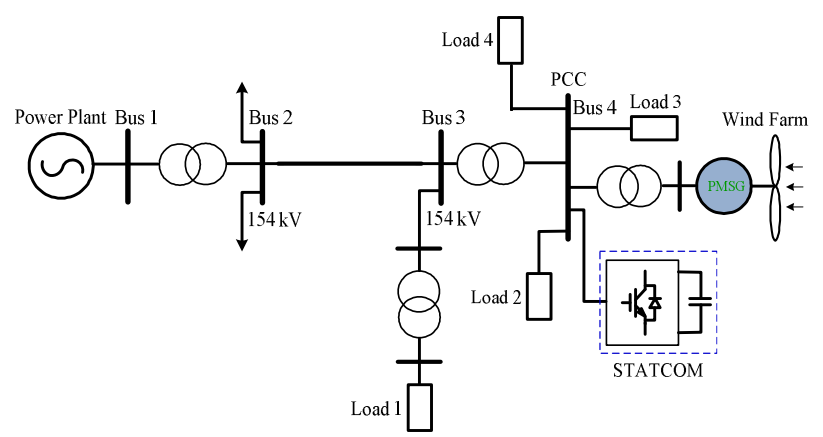

Fig. 2. Power system integrated with wind farm and STATCOM.

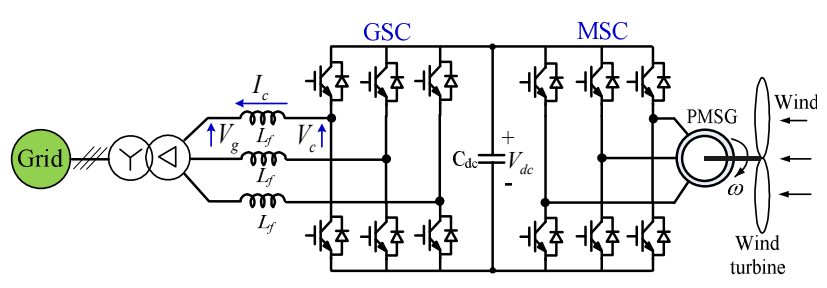

Fig. 3. PMSG wind turbine system.

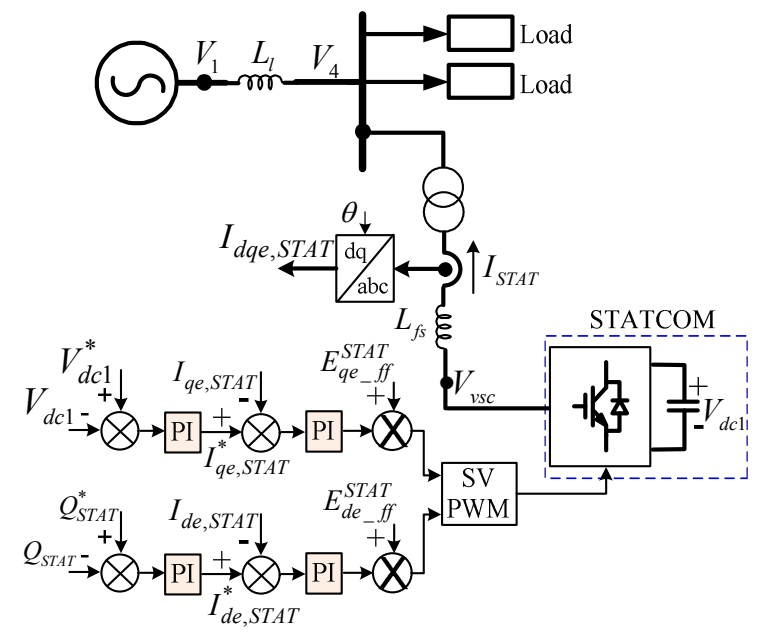

Fig. 4. Control block diagram of STATCOM.

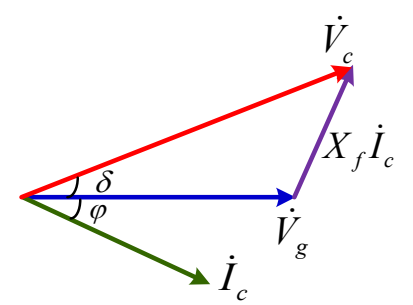

Fig. 5. Phasor diagram of the GSC.

\section{B. Reactive Power Capability of the GSC}

A typical PMSG wind turbine system is connected to the grid through a full-scale back-to-back converter as shown in Fig. 3, in which the GSC can control the active and reactive powers flowing into the grid independently. The voltage equation of the GSC is expressed as [25]:

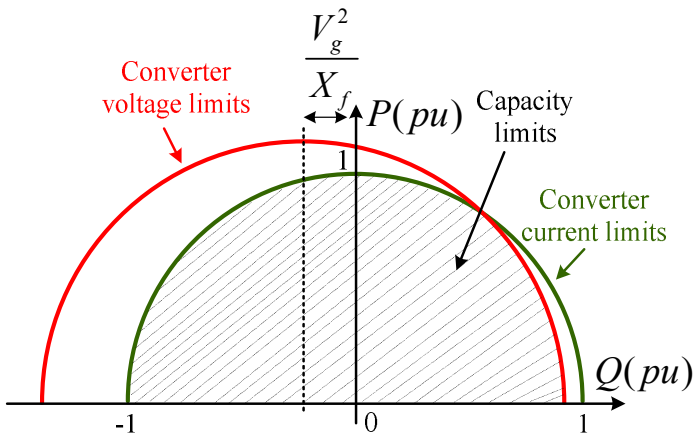

Fig. 6. Power capacity curves of the GSC.

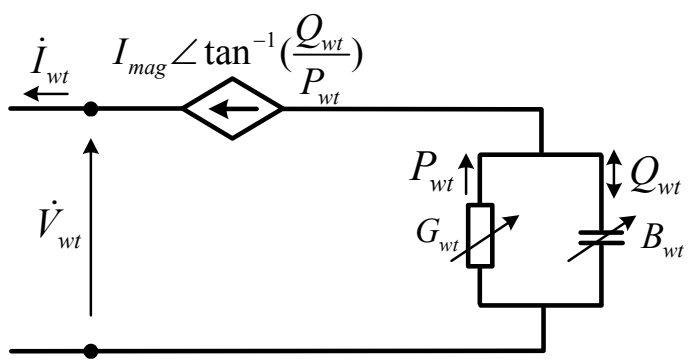

Fig. 7. Equivalent circuit of PMSG wind turbine.

$$
\dot{V}_{c}=\dot{V}_{g}+j X_{f} \dot{I}_{c}
$$

where $V_{g}$ and $V_{c}$ are the grid and converter voltages, respectively, $I_{c}$ is the converter current, $X_{f}$ is the input reactance of the GSC, and the "dot" above the variables means a complex quantity. Fig. 5 shows a phasor diagram for the GSC. By varying the amplitude and phase angle of the converter voltage, the active and reactive powers from the GSC are adjusted.

The GSC has a certain capability which is determined by the converter current and voltage. The converter current is limited by the switching devices. The power relationship under the converter current limit is expressed as:

$$
P^{2}+Q^{2}=\left(V_{g} I_{c}\right)^{2} \text {. }
$$

On the other hand, the converter voltage, which depends on the DC-link voltage of the converter, imposes another limitation on the PQ capability of the GSC. The active and reactive powers are expressed with the converter and grid voltages, respectively, as [25]:

$$
\begin{gathered}
P=\frac{V_{c} V_{g}}{X_{f}} \sin \delta \\
Q=\frac{V_{c} V_{g}}{X_{f}} \cos \delta-\frac{V_{g}^{2}}{X_{f}}
\end{gathered}
$$

where $\delta$ is the phase angle difference of the converter and grid voltages.

From (3), the relationship between $\mathrm{P}$ and $\mathrm{Q}$ under the converter voltage limit can be rewritten as: 




Fig. 8. Equivalent circuit of the power system considered.

$$
P^{2}+\left(Q+\frac{V_{g}^{2}}{X_{f}}\right)^{2}=\left(\frac{V_{c} V_{g}}{X_{f}}\right)^{2}
$$

From (2) - (5), the capacity limits of the GSC are depicted in Fig. 6. Under variable wind speeds, the active power delivered to the grid by the GSC varies. Then, the reactive power capacity of the GSC also changes.

\section{REPRESENTATION OF WIND TURBINES AND STATCOM}

In order to simplify the analysis of the influence of wind farms on a network, PMSG wind turbine systems are modeled as a load with a negative conductance and a positive or negative susceptance, which represent the active power production and the reactive power absorption or injection, respectively, as shown in Fig. 6.

In Fig. 7 , the conductance $\left(G_{w t}\right)$ and susceptance $\left(B_{w t}\right)$ represent the active and reactive powers of the wind turbine system delivered to the grid, and are given as [2]:

$$
\frac{1}{\dot{Z}_{w t}}=G_{w t}+j B_{w t}=\frac{P_{w t}+j Q_{w t}}{V_{w t}^{2}}
$$

where $Z_{w t}$ is the equivalent impedance of the wind turbine, $P_{w t}$ and $Q_{w t}$ are the active and reactive powers of the wind turbine, respectively, and $V_{w t}$ is the voltage at the wind turbine connection point. Then, the current flowing into the grid from the wind turbine, $I_{w t}$, is expressed as:

$$
\dot{I}_{w t}=I_{m a g} \angle \tan ^{-1}\left(\frac{Q_{w t}}{P_{w t}}\right)
$$

where $I_{m a g}$ is the magnitude of the wind turbine current as calculated by:

$$
I_{m a g}=\frac{\sqrt{P_{w t}^{2}+Q_{w t}^{2}}}{1.5 \cdot V_{w t}} .
$$

Similarly, the STATCOM is also modeled as a susceptance, $B_{\text {STAT }}$, which is expressed as:

$$
B_{S T A T}=\frac{Q_{S T A T}}{V_{w t}^{2}}
$$

where $Q_{S T A T}$ is the reactive power produced by the STATCOM.

\section{CoOrdinated Control Strategy of THE REACTIVE POWER BY GSCS AND STATCOM}

\section{A. PCC Voltage Regulation in the Steady State}

The equivalent circuit of the network in Fig. 2 is shown in Fig. 8, in which the transmission line reactance is modeled as $X_{l}$, and the line charging susceptance is neglected. In addition, the wind farm and the STATCOM are integrated into the network at bus 4 for providing the active and reactive powers. The load in Fig. 8 consists of the summation of the four loads shown in Fig. 2, in which the power factors of each load are assumed as $\cos \phi$. The loads are supplied mainly from the grid at bus 1 and partly from the wind turbine systems. For this network, the maximum power, $P_{\max }$, can be delivered to the load as [2]:

$$
P_{\max }=\frac{E^{2}}{X_{l}} \frac{\cos \phi}{\sqrt{(1-q)^{2}+p^{2}}-p \cos \phi+(1-q) \sin \phi}
$$

where $E$ is the rms value of the voltage at bus $1, q=$ $X_{l}\left(B_{w t}+B_{\text {STAT }}\right), p=X_{l} G_{w t}$, and $X_{l}$ is the grid impedance. Then, the voltage at bus 4 is expressed as:

$$
V_{4, P_{\max }}=\frac{1}{\sqrt{(1-q)^{2}+p^{2}}} \frac{E}{\sqrt{1+\frac{(1-q) \sin \phi-p \cos \phi}{\sqrt{(1-q)^{2}+p^{2}}}}} .
$$

At the maximum power delivered, the critical voltage at bus 4 should be kept within an allowable range (0.95 pu $1.05 \mathrm{pu}$ ). From (11), by increasing the factor $q$, which corresponds to increasing the reactive power provided from the wind farm and the STATCOM, the critical voltage at bus 4 is increased. In addition, the maximum deliverable power is increased as in (10).

Furthermore, long-term voltage fluctuations at bus 4 can be mitigated by regulating the reactive power from the wind farm and the STATCOM. For this, the voltage drop, $\Delta V$, in the transmission line is calculated as [26]:

$$
\begin{aligned}
\Delta V & =\frac{R_{l}\left(P_{L}-P_{w t}\right)+X_{l}\left(Q_{L}-Q_{S T A T}-Q_{w t}\right)}{E} \\
& \approx \frac{X_{l}\left(Q_{L}-Q_{S T A T}-Q_{w t}\right)}{E},\left(R_{l} \approx 0\right)
\end{aligned}
$$

where $P_{L}$ and $Q_{L}$ are the active and reactive powers of the load, respectively.

In order to mitigate fluctuations in the PCC voltage, the voltage drop in the transmission line should be kept constant. For example, if the voltage at bus 1 is $1.05 \mathrm{pu}$ and the voltage drop in the transmission line is $0.03 \mathrm{pu}$. Then, the PCC voltage should be kept at $1.02 \mathrm{pu}$. For this, the reactive power 


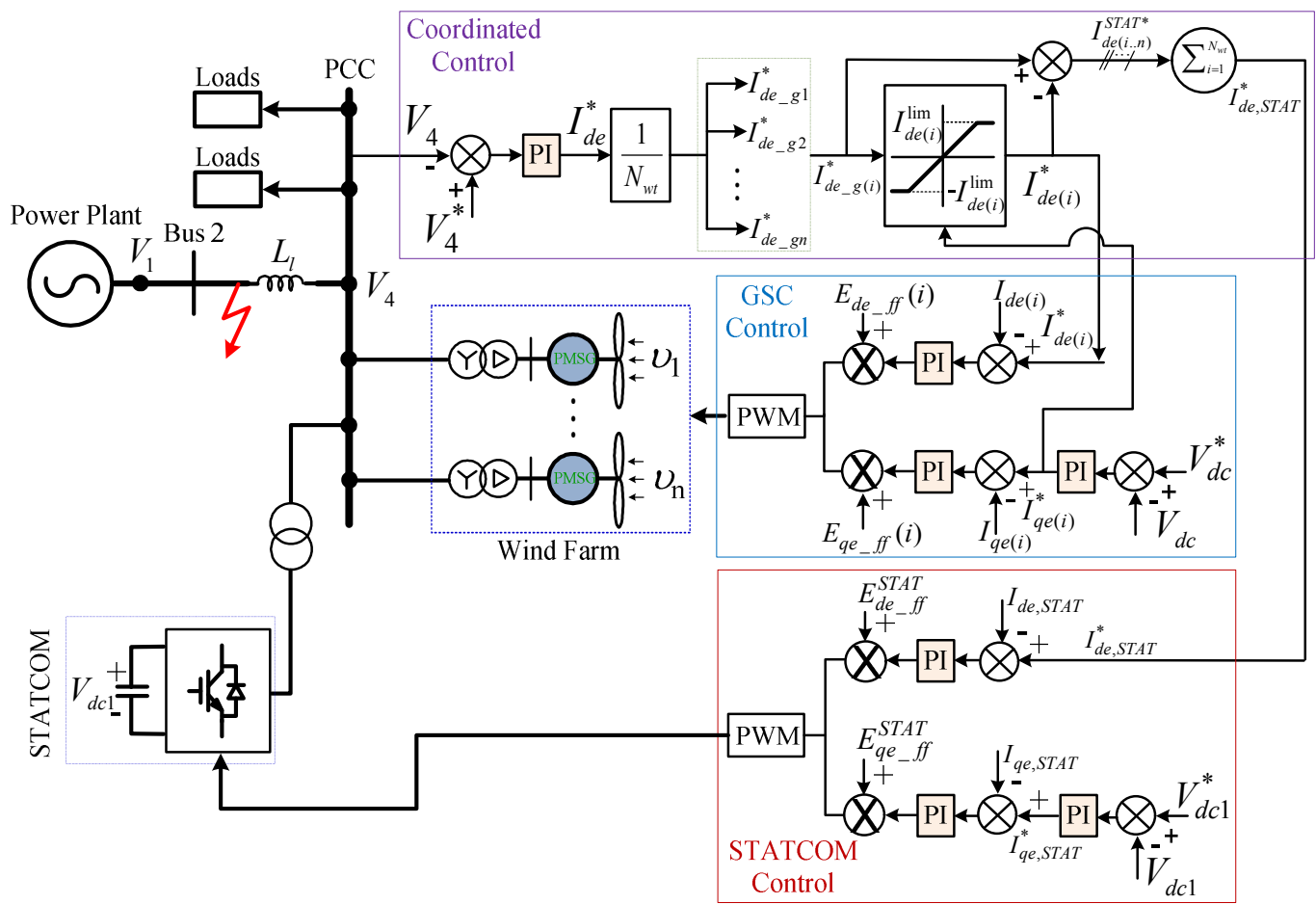

Fig. 9. Block diagram of the GSCs and the STATCOM.

required for the wind farm and the STATCOM is obtained by (12) as:

$$
Q_{\text {STAT }}+Q_{w t}=Q_{L}-\frac{\Delta V \cdot E}{X_{l}} .
$$

In the worst case where the wind speed is higher than the rated value, the active power delivered to the grid is the rated value. Then, there is no margin to produce reactive power from the GSC. In this case, from (13):

$$
Q_{S T A T}=Q_{L}-\frac{\Delta V \cdot E}{X_{l}} \text {. }
$$

However, the wind speed in the field is normally lower than the rated value. Therefore, the GSCs have the margin for supplying reactive power to regulate the PCC voltage.

Fig. 9 shows a control block diagram of the GSCs and the STATCOM. The supervisory controller manages the coordinated control of the GSCs and the STATCOM as well as the regulation of the PCC voltage. A PI (proportional and integral) regulator is used for the PCC voltage, where the reference is set as $1.02 \mathrm{pu}$. The controller output is the command of the $d$-axis current component to be injected into the network, which is supplied by the GSCs and the STATCOM coordinately.

In normal operation, the margin of the reactive power production of the GSCs depends on the amount of active power delivered to the grid. Then, the reactive current limit, $I_{d e}^{\lim }$, is constrained to the circles as shown in Fig. 5. The $q$ - axis current reference, $I_{q e}^{*}$, is decided by the power generated from the wind turbine. As mentioned previously, the PCC voltage controller generates the reference of the reactive current component, $I_{d e}^{*}$, which is shared equally by the individual GSCs.

If the capacity of the GSCs is insufficient for the command of the reactive current, the amount of the shortage is supplied from the STATCOM. Then, the reactive current reference of the STATCOM is calculated as:

$$
I_{d e, S T A T}^{*}=\sum_{i=1}^{N_{w t}} I_{d e(i)}^{S T A T^{*}}
$$

where:

$$
\begin{cases}I_{d e(i)}^{S T A T^{*}}=0 & \text {, if } I_{d e_{-} g(i)} \leq I_{d e(i)}^{\lim } \\ I_{d e(i)}^{S T A T^{*}}=I_{d e_{-} g(i)}-I_{d e(i)}^{*} & \text {, if } I_{d e_{-} g(i)}>I_{d e(i)}^{\lim }\end{cases}
$$

$I_{d e(i)}^{*}$ is the $d$-axis current reference for the GSC and $I_{d e \_g(i)}$ is the pre-set value of the $d$-axis current without considering the current limit.

With the $d$-axis current references decided from the supervisory controller, the GSCs and the STATCOM are controlled conventionally [1], as shown in Fig. 9.

\section{B. Enhancing the LVRT Capability of Wind Farms under Grid Faults}




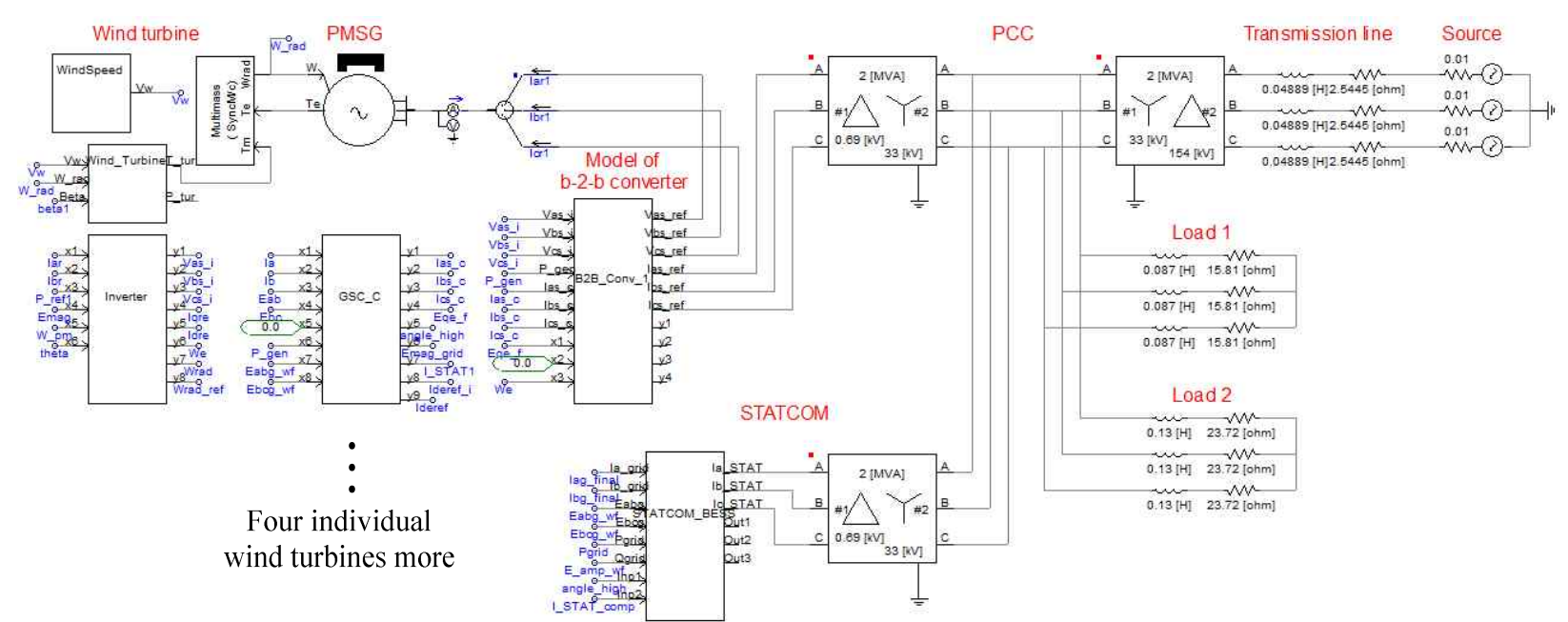

Fig. 10. PSCAD simulation model for the case study.

During a grid fault, the PCC voltage drops significantly even though the fault location is far away in the transmission line. As required by grid codes, the reactive current has to be supplied into the network to assist in the voltage recovery. In this situation, the higher the reactive current that is provided, the faster the PCC voltage is recovered. For this purpose, the STATCOM supplies the full capacity of the reactive current to the grid. In addition, the GSCs of wind turbine systems are controlled to supply the reactive current component to the grid, whereas the active current component, that is, the generator power, is reduced to zero. This is possible because the generator speed is controlled to increase, which results in a reduction of the generator power, where the turbine output power is stored in the system inertia.

\section{Simulation RESUlts}

Simulation have been carried out to verify the validity of the coordinated reactive power control scheme. PSCAD/EMTDC software has been used for the system model, which is shown in Fig. 10. The parameters of the generator, wind turbine, transmission line and transformers are listed in the Appendix. A total load connected at bus 4 is of 50-MVA at a 0.9 lagging power factor. A STATCOM rated at 9-MVA according to (14) is placed at bus 4, in which the peak current rating of the STATCOM in the low-voltage side is $9.5 \mathrm{kA}$. In this study, the coordinated control of the STATCOM and the GSCs of wind farms is investigated intensively. To achieve this some assumptions made. First, the PWM converters are modeled as current sources. Second, the current controllers in the GSC, MSC (machine-side converter) and STATCOM are operated ideally. Third, each wind turbine in the wind farm is operated at a different wind speed, as usual. (a)

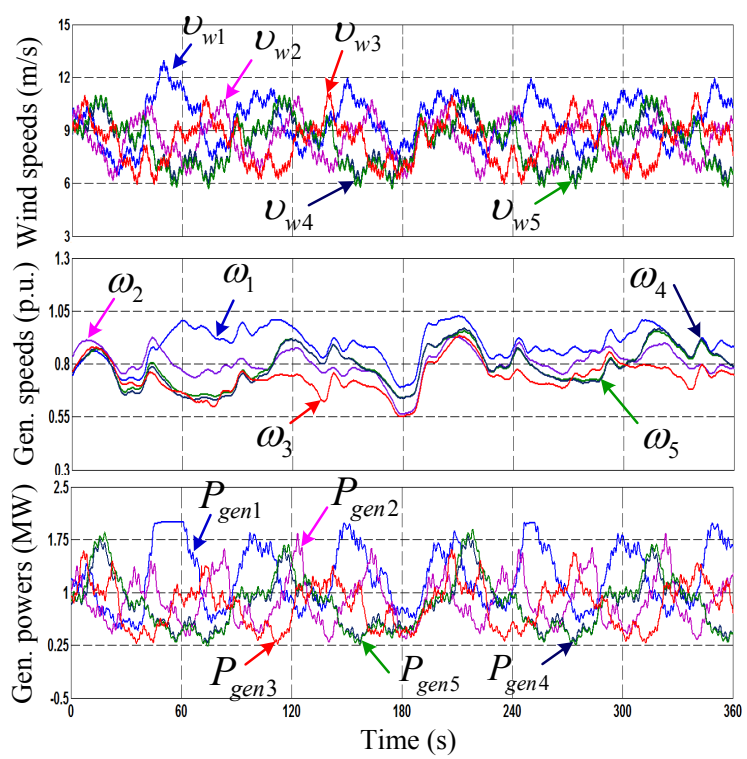

Fig. 11. Operation of the wind farm

(a) Wind speeds. (b) Generator speeds. (c) Generator powers.



Fig. 12. PCC voltages unregulated and regulated by the GSCs and the STATCOM.

The operation of each turbine under different wind speed conditions is shown in Fig. 11(a). The MPPT (maximum power point tracking) control for the individual wind turbines is performed during normal operation, where the optimal 


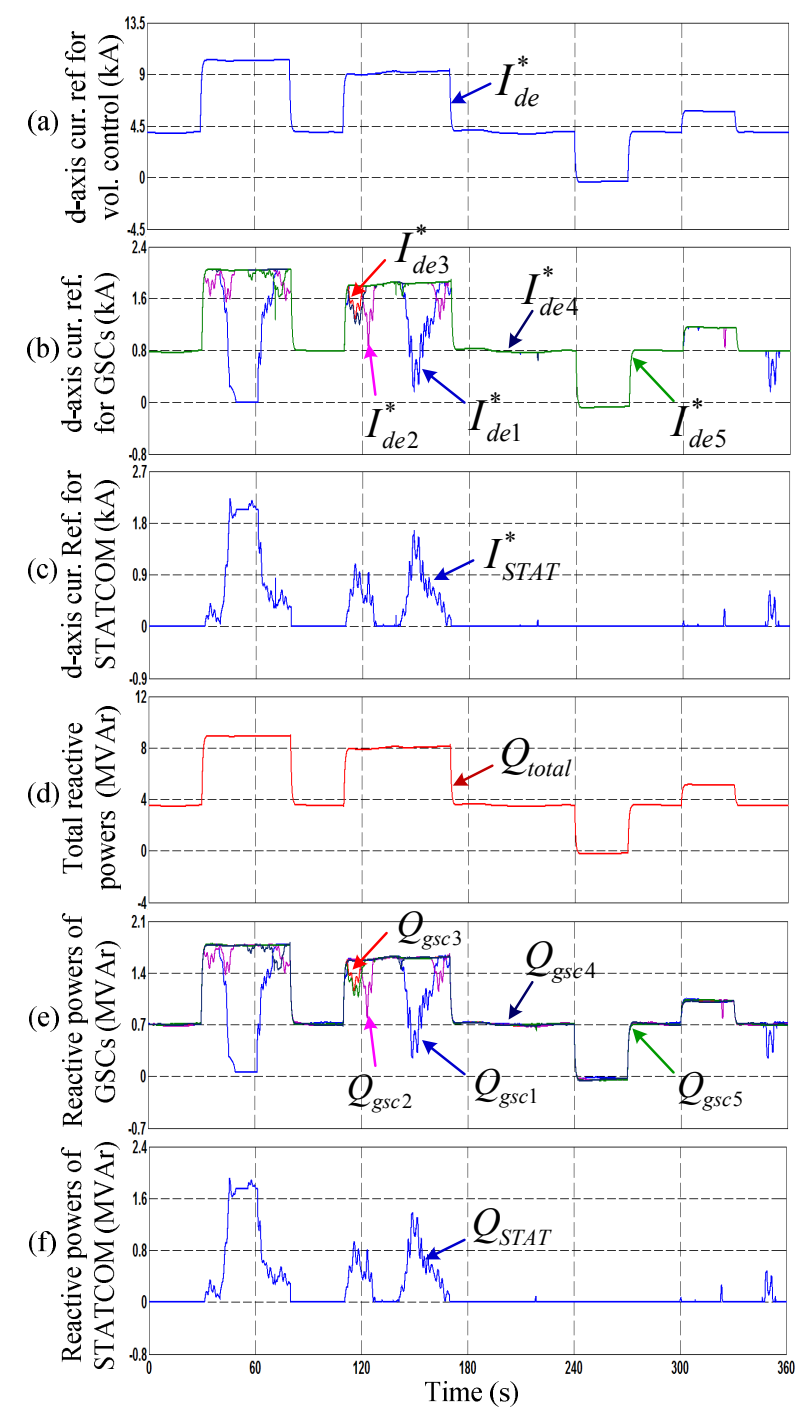

Fig. 13. Performance of coordinated control.

(a) $d$-axis current reference. (b) $d$-axis current references of the GSCs. (c) $d$-axis current reference of the STATCOM. (d) Total reactive power from the GSCs and STATCOM. (e) GSC reactive powers. (f) STATCOM reactive power.

generator speed and power are obtained, as shown in Fig. 11(b) and (c), respectively.

Fig. 12 shows the PCC voltage unregulated and regulated by the GSCs and the STATCOM. Without the control, the PCC voltage fluctuates a lot due to variations of the load or generated power fluctuations in the wind farm. On the other hand, the PCC voltage is kept well at 1.02 pu with the control of the GSCs and the STATCOM.

The PCC voltage is regulated by a PI controller, where output is the $d$-axis current reference as shown in Fig. 13(a). This current is supplied by the GSCs and the STATCOM coordinately, as shown in Fig. 13(b) and (c), respectively. The $d$-axis current reference is equally divided by the number of GSCs. However, the reactive power supplied from each GSC depends on the amount of active power delivered to the grid, where the peak current rating of each 2-MW GSC is 2.3

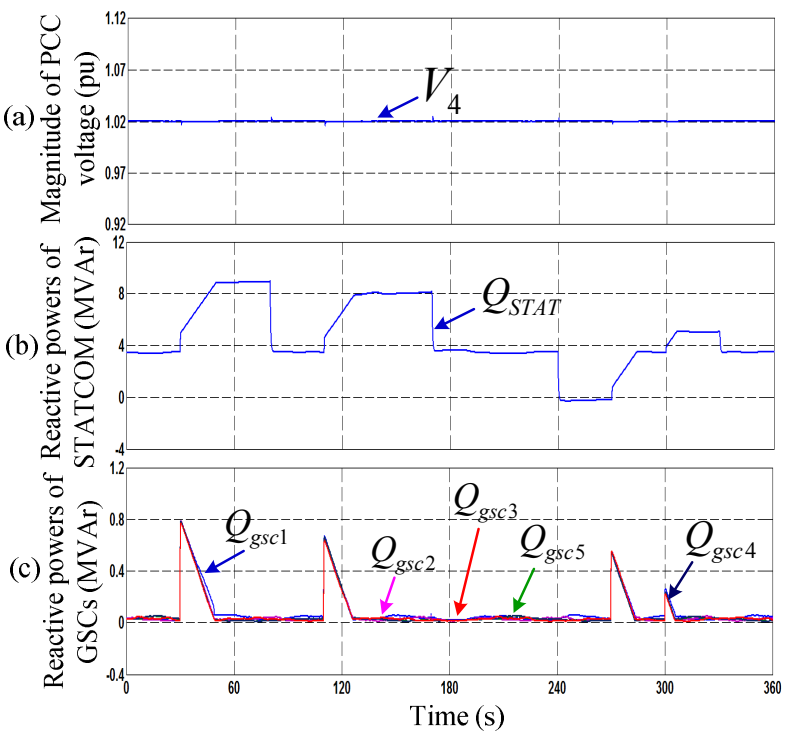

Fig. 14. PCC voltage control without coordination.

(a) Magnitude of PCC voltage. (b) STATCOM reactive power. (c) GSC reactive powers.

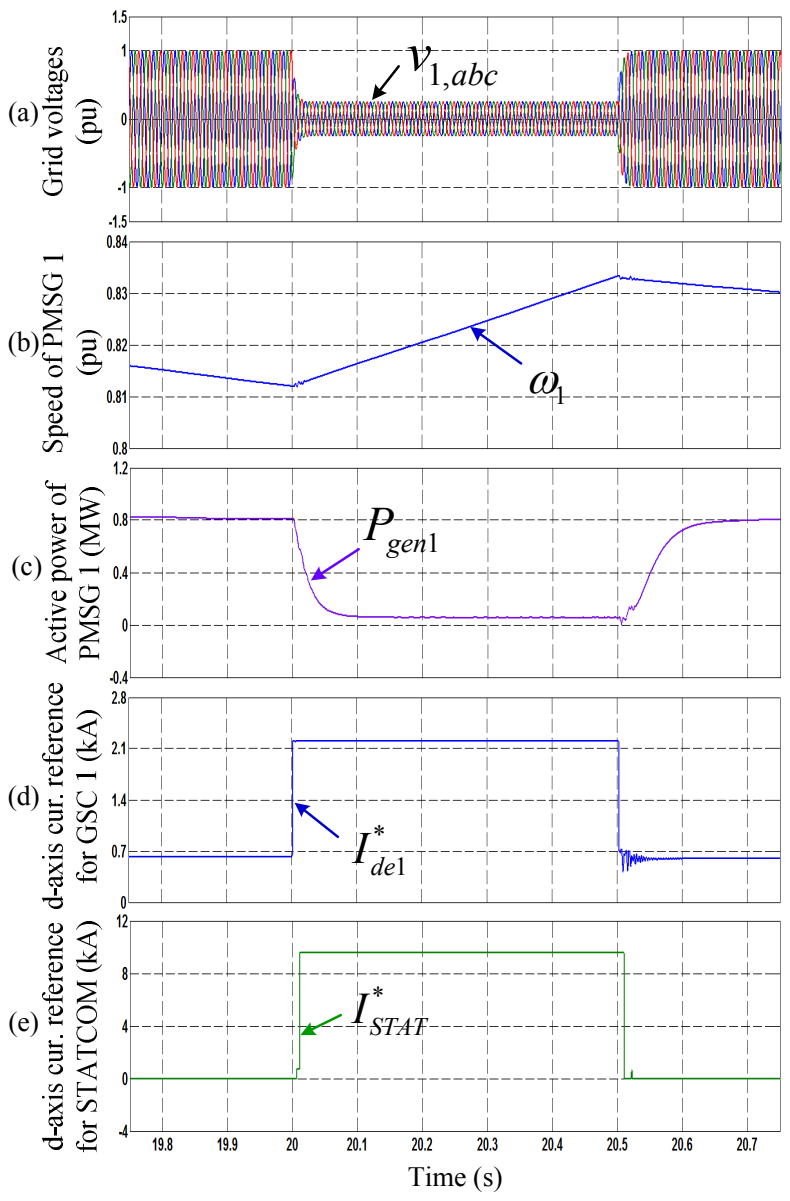

Fig. 15. Coordination of GSC and STATCOM at grid fault. (a) Grid voltages. (b) Gen. speed. (c) Gen. power. (d) $d$-axis current reference in the GSC. (e) $d$-axis current reference in the STATCOM.

kA. Therefore, the $d$-axis current reference for each GSC will 


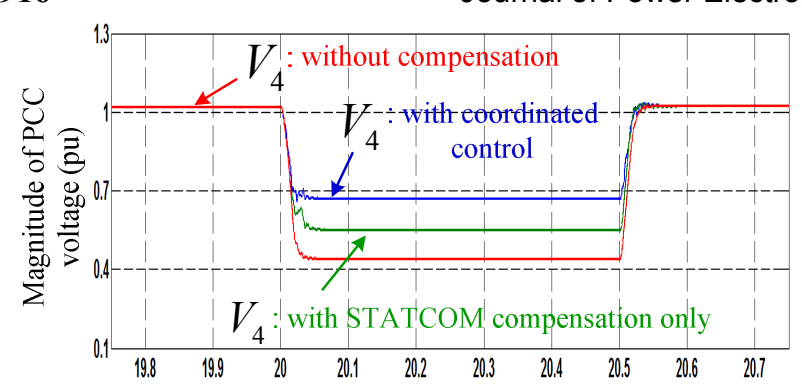

Fig. 16. PCC voltage under grid fault.

be different as shown in Fig. 13(b). Prior to activating the STATCOM, the GSCs are utilized fully according to the $d$ axis current references, while the STATCOM is in standby for this duration as shown in Fig. 13(c), where the capacity of the GSCs is sufficient to regulate the PCC voltage. Fig. 13(d) shows the total reactive power supplied to the network from the GSCs and the STATCOM. The reactive powers of the GSCs and the STATCOM are shown in Fig. 13(e) and (f), respectively, and are proportional to the $d$-axis currents shown in Fig. 13(b) and (c).

In addition, $\mathrm{PCC}$ voltage control without the coordination of the GSCs and the STATCOM is investigated, which is shown in Fig. 14. The PCC voltage is controlled well at its normal value of $1.02 \mathrm{pu}$ as shown in Fig. 14(a). For this, the STATCOM and the GSCs supply reactive power to the grid independently, where the PCC voltage controllers are used on the both sides of the STATCOM and the GSCs [1], [27]. Fig. 14(b) and (c) shows the reactive powers supplied from the STATCOM and the GSCs, respectively, where the STATCOM is operated to supply reactive power all the time. This causes an increase in the power losses of the STATCOM. In addition, the lifetime of the devices in the STATCOM will be reduced due to the continuous operation.

Next, the LVRT capability of a wind farm integrated with the grid is investigated in transient states, where it is considered that a three-phase voltage sag occurs on the transmission line between bus 2 and 3. Fig. 15 shows the coordinated control performance of the wind farm and the STATCOM during a grid fault, in which the three-phase grid voltages are shown in Fig. 15(a). During the grid fault, the reactive power is prioritized to supply the grid. For this, the generator speed is increased as shown in Fig. 15(b). This causes a reduction of the generator output power as shown in Fig. 15(c). Then, the control of the GSCs is modified to provide reactive current for the grid voltage recovery. Fig. 15(d) shows the $d$-axis current reference of the GSC. In addition, the STATCOM provides the reactive current fully as shown in Fig. 15(e).

Fig. 16 shows the PCC voltages during the fault. It can be seen that the PCC voltage rise with the STATCOM compensation is higher than the rise without this compensation. With the coordinated reactive power control of the STATCOM and the GSCs, the PCC voltage is greatly improved when compared with the other cases. It is noted
TABLE I. PARAMETERS OF PMSG

\begin{tabular}{|c|c|}
\hline Rated power & $2 \mathrm{MW}$ \\
\hline Stator voltage/frequency & $690 \mathrm{~V} / 16.6 \mathrm{~Hz}$ \\
\hline Stator resistance & $0.008556 \Omega$ \\
\hline Stator inductance & $0.00359 \mathrm{H}$ \\
\hline Number of poles & 120 \\
\hline Moment of inertia & $48,500 \mathrm{~kg} . \mathrm{m}^{2}$ \\
\hline
\end{tabular}

TABLe II. Parameters of TURbine Blades

\begin{tabular}{|c|c|}
\hline Blade radius & $42 \mathrm{~m}$ \\
\hline Air density & $1.225 \mathrm{~kg} / \mathrm{m}^{3}$ \\
\hline Max. power conv. coefficient & 0.40 \\
\hline Optimal tip-speed ratio & 7.0 \\
\hline Rated wind speed & $12 \mathrm{~m} / \mathrm{s}$ \\
\hline Moment of inertia & $6.3 \cdot 10^{6} \mathrm{~kg} \cdot \mathrm{m}^{2}$ \\
\hline
\end{tabular}

that in order to fully recover the grid voltage during a grid fault, the required capacity of the STATCOM is extremely large (about 50 MVA in the studied system). However, this requirement from the grid code is not mandatory.

\section{CONCLUSIONS}

A novel coordinated reactive power control for the GSCs and the STATCOM of wind farms has been proposed to enhance the PCC voltage regulation in both steady-state and transient-state conditions, where the GSCs are utilized fully to provide reactive power for the grid prior to activating the STATCOM. With this coordinated control scheme, the continuous operation of the STATCOM is not mandated, resulting in an increase in the lifetime of the devices. In addition, by prioritizing the reactive current injection from the GSCs during grid faults, the grid voltage is recovered faster without the requirement of a large-sized STATCOM. The validity of the proposed algorithm has been verified by simulation results.

\section{APPENDIX}

The parameters of the generators and wind turbine used for the simulation are listed in Table I and II, respectively. In addition, the parameters of the transmission lines are listed as follows:

Distribution transformer: $154 / 33 \mathrm{kV}, 100 \mathrm{MVA}$, reactance $=5 \%$; wind turbine transformer: $33 / 0.69 \mathrm{kV}, 2 \mathrm{MVA}$, reactance $=6.0 \%$; transmission line: $X_{l}=6.5 \%$.

\section{REFERENCES}

[1] W. Qiao, R. G. Harley, and G. K. Venayagamoorthy, "Coordinated reactive power control of a large wind farm and a STATCOM using heuristic dynamic programming," IEEE Trans. Energy Convers., Vol. 24, No. 2, pp. 493-503, Jun. 2009. 
[2] N. R. Ullah and T. Thiringer, "Variable speed wind turbines for power system stability enhancement," IEEE Trans. Energy Convers., Vol. 22, No. 1, pp. 52-60, Mar. 2007.

[3] M. Tsili and S. Papathanassiou, "A review of grid code technical requirements for wind farms," IET Renew. Power. Gener., Vol. 3, No. 3, pp. 308-332, Sep. 2009.

[4] T. H. Nguyen and D. C. Lee, "Ride-through technique for PMSG wind turbine using energy storage systems", Journal of Power Electronics, Vol. 10, No. 6, pp. 733-738, Nov. 2010.

[5] T. H. Nguyen and D. C. Lee, "Advanced fault ride-through technique for PMSG wind turbine systems using line-side converter as STATCOM," IEEE Trans. Ind. Electron., Vol. 60, No. 7, pp. 2842-2850, Jul. 2013.

[6] G. Tapia, A. Tapia, and J. X. Ostolaza, "Proportionalintegral regulator-based approach to wind farm reactive power management for secondary voltage control," IEEE Trans. Energy Convers., Vol. 22, No. 2, pp. 488-498, Jun. 2007.

[7] T. Ackermann, Ed., Wind power in power systems. West Sussex, U.K.: Willey, 2005.

[8] J. M. Carrasco, L. G. Franquelo, J. T. Bialasiewicz, E. Galvan, R. C. P. Guisado, M. A. M. Prats, J. I. Leon, and N. M. Alfonso, "Power-electronic systems for the grid integration of renewable energy sources: a survey," IEEE Trans. Ind. Electron., Vol. 53, No. 4, pp. 1002-1016, Aug. 2006.

[9] S. Engelhardt, I. Erlich, C. Feltes, J. Kretschmann, and F. Shewarega, "Reactive power capability of wind turbines based on doubly fed induction generators," IEEE Trans. Energy Convers., Vol. 26, No. 1, pp. 364-372, Mar. 2011.

[10] R. G. de Almedia, E. D. Castronuouvo, and J. A. P. Lopes, "Optimum generation control in wind parks when carrying out system operator requests," IEEE Trans. Power Syst., Vol. 21, No. 2, pp. 718-725, May 2006.

[11] F. D. Kanellos and N. D. Hatziargyriou, "Optimal control of variable speed wind turbines in islanded mode of operation," IEEE Trans. Energy Convers., Vol. 25, No. 4, pp. 1142-1151, Dec. 2010.

[12] G. Gerdes , and F. Santjer, "Power quality of wind turbines and their interaction with the grid", in Proc. Eur. Wind Energy Conf., 14-16, Thessaloniki, Greece, pp. 1152-1157, Oct. 1998

[13] C. Han, A. Q. Huang, M. E. Baran, S. Bhattacharya, W. Litzenberger, L. Anderson, A. L. Johnson, and A. A. Edris, "STATCOM impact study on the integration of a large wind farm into a weak loop power system," IEEE Trans. Energy Convers., Vol. 23, No. 1, pp. 226-233, Mar. 2008.

[14] M. Kayikci and J. V. Milanovic, "Reactive power control strategies for DFIG-based plants," IEEE Trans. Energy Convers., Vol. 22, No. 2, pp. 389-396, Jun. 2007.

[15] N. R. Ullah, T. Thiringer, and D. Karlsson, "Voltage and transient stability support by wind farms complying with the E.ON netz grid code," IEEE Trans. Power Syst., Vol. 22, No. 4, pp. 1647-1656, Nov. 2007.

[16] H. Xie, L. Angquist, and H. P. Nee, "Design study of a converter interface interconnecting energy storage with the DC link of a STATCOM," IEEE Trans. Power Del., Vol. 26, No. 4, pp. 2676-2686, Oct. 2011.

[17] M. N. Slepchenkov, K. M. Smedley, and J. Wen, "Hexagram-converter-based STATCOM for voltage support in fixed-speed wind turbine generation systems," IEEE Trans. Ind. Electron., Vol. 58, No. 4, pp. 1120-1131, Apr. 2011.
[18] M. M. Montazeri and D. Xu, "Coordination of DFIG and STATCOM in a power system," in Proceeding of IEEE ISIE, pp. 993-998, 2012.

[19] H. Amaris and M. Alonso, "Coordinated reactive power management in power networks with wind turbines and FACTS devices," Energy Convers. Manage., Vol. 52, pp. 2575-2586, 2011.

[20] A. M. Munoz, Power quality: mitigation technologies in a distributed environment, Springer, 2007, Chap. 7.

[21] Q. Song and W. Liu, "Control of a cascade STATCOM with star configuration under unbalanced conditions," IEEE Trans. Power Electron., Vol. 24, No. 1, pp. 45-58, Jan. 2009.

[22] M. Molinas, J. A. Suul, and T. Undeland, "Low voltage ride-through of wind farms with cage generators: STATCOM versus SVC," IEEE Trans. Power Electron., Vol. 23, No. 3, pp. 1104-1117, May 2008.

[23] B. Gultekin and M. Ermis, "Cascaded multilevel converterbased transmission STATCOM: system design methodology and development of a $12 \mathrm{kV} \pm 12 \mathrm{MVAr}$ power stage," IEEE Trans. Power Electron., Vol. 28, No. 11, pp. 4930-4950, Nov. 2013.

[24] Z. Chen, F. Blaabjerg, Y. Hu, "Stability improvement of wind turbine system by STATCOM," IEEE Ind. Electron., IECON 2006 - 32nd Annual Conference, pp. 4213-4218, Nov. 2006.

[25] P. Kundur, Power system stability and control, New York: McGraw-Hill, 1993.

[26] W. Hu, Z. Chen, Y. Wang, and Z. Wang, "Flicker mitigation by active power control of variable-speed wind turbines with full-scale back-to-back power converters," IEEE Trans. Energy Convers., Vol. 24, No. 3, pp. 640-649, Sep. 2009

[27] N. G. Hingorani and L. Gyugyi, Understanding FACTS: Concept and Technology of Flexible AC Transmission Systems. New York: IEEE, 2000.

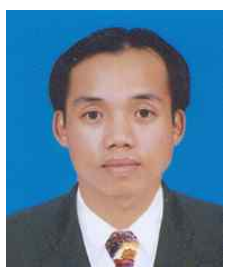

Thanh Hai Nguyen was born in Dong Thap, Vietnam. He received his B.S. in Engineering from the Ho Chi Minh City University of Technology, Ho Chi Minh City, Vietnam, in 2003, and his M.S. and Ph.D. in Electrical Engineering from Yeungnam University, Gyeongbuk, Korea, in 2010 and 2013, respectively, where he is currently working as a Research Professor $\mathrm{He}$ was an Assistant Lecturer in the College of Technology, Can Tho University, Can Tho, Vietnam, from May 2003 to February 2008. His current research interests include power converters, machine drives, and wind power generation.

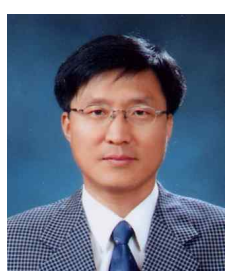

Dong-Choon Lee received his B.S., M.S., and Ph.D. in Electrical Engineering from Seoul National University, Seoul, Korea, in 1985, 1987, and 1993, respectively. He was a Research Engineer with Daewoo Heavy Industry, Korea, from 1987 to 1988. Since 1994, he has been a faculty member in the Department of Electrical Engineering, Yeungnam University, Gyeongbuk, Korea. As a Visiting Scholar, he joined the Power Quality Laboratory, Texas A\&M University, College Station, TX, USA, in 1998, the Electrical Drive Center, University of Nottingham, Nottingham, UK, in 2001, the Wisconsin Electric Machines \& Power Electronic Consortium, University of Wisconsin, Madison, WI, USA, in 2004, and the 
FREEDM Systems Center, North Carolina State University, Raleigh, NC, USA, from September 2011 to August 2012. His current research interests include ac machine drives, control of power converters, wind power generation, and power quality. Prof. Lee is currently a Publication Editor of the Journal of Power Electronics of the Korean Institute of Power Electronics.

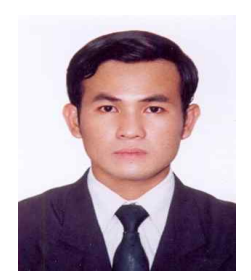

Tan Luong Van received his B.S. and M.S. in Electrical Engineering from the Ho Chi Minh City University of Technology, Ho Chi Minh City, Vietnam, in 2003 and 2005, respectively, and his Ph.D. in Electrical Engineering from Yeungnam University, Gyeongbuk, Korea, in 2013. He is currently a Lecturer at Ho Chi Minh City Electric Power College, Ho Chi Minh City, Vietnam. His current research interests include power converters, machine drives, wind power generation, power quality and power systems.

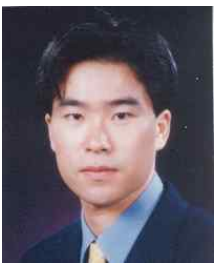

Jong-Ho Kang received his B.S. in Electrical and Electronics Engineering from Chung-Ang University, Seoul, Korea, in 2001, and his M.S. and Ph.D. in Electrical Engineering from Seoul National University, Seoul, Korea, in 2004, and 2009, respectively. He was a Research Engineer with Hyundai Heavy Industries, from 2001 to 2002 . He has worked as a Head Engineer in the Electrical System Department of the Wind-Turbine Business in Hyosung Cooperation, since 2010. In addition, he has done research on electric power systems as a member of CIGRE (Conseil International des Grands Reseaux Electriques). His current research interests include large scale electrical machine design, high power converters, wind turbine control including wind farm control and analysis of intelligent power grid systems. 